\title{
Effect of mesoporous silica under Neisseria meningitidis transformation process: environmental effects under meningococci transformation
}

\author{
Luciana M Hollanda', Gisele CG Cury', Rafaella FC Pereira', Gracielle A Ferreira², Andreza Sousa², Edesia MB Sousa ${ }^{2}$ \\ and Marcelo Lancellotti ${ }^{*}$
}

\begin{abstract}
Background: This study aimed the use of mesoporous silica under the naturally transformable Neisseria meningitidis, an important pathogen implicated in the genetic horizontal transfer of DNA causing a escape of the principal vaccination measures worldwide by the capsular switching process. This study verified the effects of mesoporous silica under $N$. meningitidis transformation specifically under the capsular replacement.

Methods: we used three different mesoporous silica particles to verify their action in N. meningitis transformation frequency.

Results: we verified the increase in the capsular gene replacement of this bacterium with the three mesoporous silica nanoparticles.
\end{abstract}

Conclusion: the mesouporous silica particles were capable of increasing the capsule replacement frequency in $\mathrm{N}$. meningitidis.

\section{Findings}

Freshly isolated Neisseria meningitidis are naturally competent and exchange genetic information with each other by this process. They are also known as a commensal bacterium of the human upper respiratory tract that may occasionally provoke invasive infections such as septicemia and meningitis. This natural competence has been directly correlated to pilliation of these organisms [1] as well as a specific uptake sequence contained multifold within the genome of these bacteria. Pilliated strains are easily transformed by direct incubation with a plasmid containing the uptake sequence or chromosomal DNA [2]. The advantages of doing genetic manipulations within these well-known strains are numerous. Development of systems to construct specific genomic mutations has been used to study their pathogenesis [3-5].

\footnotetext{
* Correspondence: mlancell@unicamp.br

'Department of Biochemistry, Institute of Biology CP6109, State University of Campinas UNICAMP, CP: 6109-CEP 13083-970, Campinas, SP, Brazil
} Full list of author information is available at the end of the article
The use of the mutations for the study of the capsular polysaccharide of $N$. meningitidis allowed the advances in the meningococci pathogenesis understandings [6-8]. The capsular polysaccharide is a major virulence factor and a protective antigen. Meningococcal strains are classified into 12 different serogroups according to their capsular immune specificity, among wich the serogroups A, B, C, Y and W135 are the most frequently found in invasive infections. The capsule of serogroups B, C, Y and W135 strains is composed of either homopolymers (B and $\mathrm{C}$ ) or heteropolymers (Y and W135) of sialic acid-containing polysaccharides that are specifically linked, depending on the serogroup [9-11]. This polymerization is mediated by the polysialyltransferase, encoded by the siaD gene in strains of serogroups B and C (also called synD and synE, respectively) and by syn $G$ in serogroup W135. Capsule switching after replacement of $\operatorname{syn} E$, in a serogroup C strain, by syn $G$ may result from the conversion of capsule genes by transformation and allelic recombination $[3,12,13]$. The capsule switching from serogroup $\mathrm{C}$ to $\mathrm{B} N$. meningitidis was

\section{C) Biomed Central}


observed in several countries after vaccination campaigns [3,14-17]. It might explain the emergence and the clonal expansion of strains of serogroup W135 of $N$. meningitidis in the year 2000 among Hajj pilgrims who had been vaccinated against meningococci of serogroups $\mathrm{A}$ and $\mathrm{C}$ $[11,18]$. These W135 strains belong to the same clonal complex ET-37/ST-11 as prominent serogroup C strains involved in outbreaks worldwide [12,19]. Hence, the emergence of these W135 strains in epidemic conditions raised the question about a possible capsule switching as an escape mechanism to vaccine-induced immunity. Also, these events are expected to occur continuously and can be selected by immune response against a particular capsular polysaccharide [11]. However, the interference of immune response with transformation efficacy has not yet been evaluated. Specific capsular antibodies are expected to bind to the bacterial surface and hence the interference in DNA recognition and uptake.

In addition, environmental interference on the transformation process of this bacterium is also unknown. This work aimed at the use of different mesoporous silica SBA-15, SBA-16 and [SBA-15/P(N-iPAAm)], an organicinorganic hybrids systems based on mesoporous materials and stimuli-responsive polymers, for the study of these nanostructures effect on the transformation process of meningococci, specifically their functions on capsular switching process. Mesoporous silica materials are a fairly new type of material that has pores in the mesoscopic range of 2-50 $\mathrm{nm}$. The characteristic features of ordered mesoporous materials are their monodispersed and adjustable pore size in an inert and biocompatible matrix with an easily modified surface. The intrinsic uniform porous structure of this class of compounds with their large specific surface area and pore volume, associated with surface silanol groups, makes these materials suitable as an adsorbent model for studies involving surface phenomena. The methods used in this work verified the effect of mesoporous silica SBA-15, SBA-16 and [SBA$15 / \mathrm{P}(N$-iPAAm $)]$ on the transformation of the serogroup C N. meningitidis against two different donor DNA obtained from mutants of this microorganism (M2 and M6).
The characteristics of the strains (N. meningitidis and Escherichia coli) used in this study are described in Table 1. N. meningitidis were grown at $37^{\circ} \mathrm{C}$ under $5 \% \mathrm{CO} 2$ on GCB agar medium (Difco) containing the supplements described by Taha et al, [20]. When needed, culture media were supplemented with erythromycin at $2 \mu \mathrm{g} / \mathrm{ml}$ and spectomycin at $40 \mu \mathrm{g} / \mathrm{ml}$. E. coli strains used for plasmid preparations were $\mathrm{DH} 5 \boldsymbol{\alpha}$.

The mesoporous silica nanoparticles SBA-15, SBA-16 and $[$ SBA-15/P(N-iPAAm) $]$ were characterized by Sousa et al. [21]. Both, SBA-15 and SBA-16 are composed of $\mathrm{SiO}_{2}$ but the characteristic features of SBA-15 are the presence of channels arranged in a two-dimensional hexagonal structure and wheat like macroscopic morphology with mean sizes in micrometer scale which consist of many ropelike aggregates. On the other hand, SBA-16 is an example of ordered mesoporous silica with a three dimensional cubic cage structure with three dimensional channel connectivity. Also, in SBA-16 the arrays of the ordered and uniform pores can be observed for which each spherical particle is a single crystal arranged in cubic structure.

The SEM images of SBA15 evidence the presence of elongated, $590 \mathrm{~nm}$-wide vermicular shaped particles. SBA15 consists of many rope-like domains with average sizes of $1.7 \mu \mathrm{m}$ aggregated into wheat-like macrostructures, Figure 1(a). A similar morphology is observed after the polymerization of $\mathrm{P}(\mathrm{N}$-iPAAm) inside the SBA-15 network, presenting $450 \mathrm{~nm}$ width (data not showed). TEM image of SBA-15 shows a well-defined hexagonal arrangement of uniform pores when the incident electron beam was parallel to the main axis of the mesoporous (Figure $1 b)$, and unidirectional channels, when the electron beam was perpendicular to the channel axis (Figure 1c). The SBA-16 particle observed from SEM exhibits rounded shape with diameter size between 15 and $20 \mu \mathrm{m}$ with an "aggregated morphology". The corresponding TEM images of the SBA-16, Figure 2, showed well arranged cubic mesopores what confirmed the 3D cubic pore structure.

Some mesoporous textural properties of SBA-15 and SBA-16 were obtained by the nitrogen adsorption measure. Table 2 summarizes these properties of SBA-15 and

Table 1 Bacterial Strains used in this work

\begin{tabular}{|c|c|c|}
\hline Strain & Characteristics & Origin (Reference) \\
\hline $\mathrm{DH} 5 \propto$ & Escherichia coli F-, endA1, hsdR17 c, supE44, thi-1, gir A96, relA1 & [44] \\
\hline pLAN45 & Plasmid containing $\triangle \mathrm{NMB0065:: \Omega aaDA}$ & This work \\
\hline pLAN13 & Plasmid containning the fusion of synG.:ermAM & This work \\
\hline C2135 & Neisseria meningitidis serogroup C, BIOMERIEUX & INCQS-FIOCRUZ \\
\hline W135 $5_{\text {ATCC }}$ & Neisseria meningitidis serogroup W135, ATCC35559 & INCQS-FIOCRUZ \\
\hline M2 & N.meningitidis isogenic mutant $\triangle \mathrm{NMB0065::} \mathrm{\Omega aaDA}$ & This work \\
\hline M6 & W135 ATCC transformed with pLAN13 to generate a fusioned strain synG:ermAM & This work \\
\hline
\end{tabular}




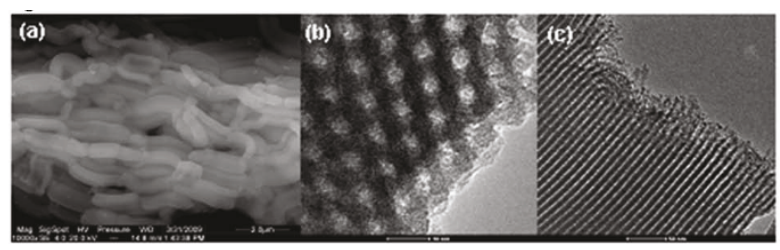

Figure 1 (a) SEM image of SBA-15 which evidence the presence of elongated, vermicular shaped particles $590 \mathrm{~nm}$ wide. TEM image of SBA-15, which shows a well-defined hexagonal arrangement of uniform pores when (b) the incident electron beam was parallel to the main axis of the mesopores and unidirectional channels, and (c) the electron beam was perpendicular to the channel axis.

SBA-16. BET-specific surface area, $\mathrm{S}_{\mathrm{BET}}$, was calculated from adsorption data in the relative pressure interval $\mathrm{P} / \mathrm{P}_{0}$ $=0.045-0.25$. A cross-sectional area of $0.162 \mathrm{~nm}^{2}$ was used for the nitrogen molecule in the BET calculations. The total pore volume, $\mathrm{V}_{\mathrm{p}}$, was calculated from the amount of $\mathrm{N}_{2}$ adsorbed at the highest $\mathrm{P} / \mathrm{P}_{0}\left(\mathrm{P} / \mathrm{P}_{0}=0.99\right)$. The pore diameter, $\mathrm{D}_{\mathrm{BJH}}$, was calculated using the adsorption branches of the nitrogen isotherms employing the $\mathrm{BJH}$ algorithm. SBA-15, SBA-16 and SBA-15/P(N-iPAAm) have small pore diameters from 3.7 to $5.7 \mathrm{~nm}$ with very narrow pore size distributions (data not shown). Total pore volumes for SBA-15, SBA-16 and SBA-15/P $(N-$ iPAAm) can also be calculated to be $0.96 \mathrm{~cm}^{3} / \mathrm{g}, 0.49 \mathrm{~cm}^{3} /$ $\mathrm{g}$ and $0.48 \mathrm{~cm}^{3} / \mathrm{g}$, respectively. SBA-15 has a higher surface area than the SBA-16 and SBA-15/P(N-iPAAm).

Recombinant DNA protocols as cloning plasmids, PCR amplifications, insertion of resistance cassettes and transformation were performed as described previously $[20,22]$. The oligonucleotides used are listed in Table 3. All the mutants obtained by homologous recombination were checked by PCR analysis using a oligonucleotide harboring the target gene and another harboring the cassette. The Figures 3 and 4 describe the design of mutants-M2 and M6, respectively, whose genomic DNA

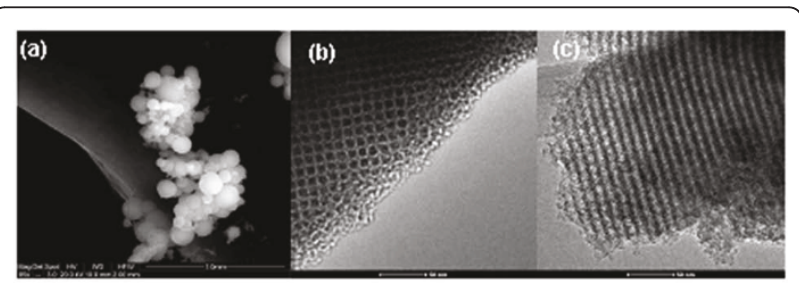

Figure 2 (a) SEM image of SBA-16 exhibits rounded shape with diameter size between 15 and $20 \mu \mathrm{m}$ and of an "aggregated morphology". TEM images of SBA-16 showed well ordered cubic mesoporous which confirmed the 3D cubic pore structure, when (b) viewed along the pore axis and (c) perpendicularly to the pore axis.
Table $2 \mathbf{N}_{2}$ adsorption results

\begin{tabular}{cccc}
\hline Sample & $\mathrm{D}_{\mathrm{BJH}}(\mathrm{nm})$ & $\mathrm{S}_{\mathrm{BET}}\left(\mathrm{m}^{\mathbf{2}} \cdot \mathbf{g}^{-\mathbf{1}}\right)$ & $\mathrm{V}_{\mathbf{p}}\left(\mathrm{cm}^{\mathbf{3}} \cdot \mathbf{g}^{-\mathbf{1}}\right)$ \\
\hline SBA-16 & 3.7 & 550 & 0.49 \\
\hline SBA-15 & 5.7 & 672 & 0.96 \\
\hline SBA-15/P(N-iPAAm) & 3.7 & 326 & 0.48 \\
\hline
\end{tabular}

$\mathrm{S}_{\mathrm{BE}} T$ is the specific area, $\mathrm{D}_{\mathrm{BJH}}$ is the average pore diameter and $\mathrm{V}_{\mathrm{p}}$ is the average pore volume.

were extracted for gene transfer in C2135 receptor strain.

A preliminary analysis of the action of the mesoporous silica was performed to determine the influence of this nanostructure under Neisseria meningitidis growth. The results did not show any influence on bacterial growth of the presence of DNA in addition of SBa15, SBa16 or SBA-15/P(N-iPAAm) (data not showed).

The first mutant referent to NMB0065 sequence mutants was the strain M2, this mutant had the NMB0065 sequence from $N$. meningitidis C2135 amplified using 03.12-3 and 03.12-4 oligonucleotides (Table 3). This fragment was cloned into the pGEM-T Easy Vector System II (Promega Corporation, Madison, WI, USA), to generate the plasmid pLAN6. E. coli strain Z501 was transformed with plasmid pLAN6 resulting in the plasmid pLAN7. The $\Omega a a D A$ cassette was inserted into the $B c l I$ site of pLAN7 to generate plasmid pLAN45, which was transformed into the $\mathrm{C} 2135$ strain to generate the strain M2 (Figure 3).

The construction of serogroup W135 mutants with transcriptional fusion synG:: $\operatorname{erm} A M$ was initiated by amplifying the region of $\operatorname{syn} G$ gene using the 98-30 and 03-12-5 oligonucleotides (Table 3) on DNA from the serogroup W135atcc strain. The amplified fragment was cloned into the pGEM-T Easy Vector System I (Promega, Madison, WI, USA), to generate the plasmid pLAN11. Another fragment was amplified using the 0402-2/galECK29A from synG downstream sequence, cloned into pGEM-T Easy Vector, to generate pLAN52. The ermAM cassette was amplified by ERAM1/ERAM3 and insered into NcoI site of pLAN52 to generate pLAN53. The fragment amplified from pLAN53 with the ERAM1 and galECK29A [23] was inserted into PstI site of pLAN11 to generate pLAN13-2. This plasmid was linearised by the enzyme SphI and transformed into

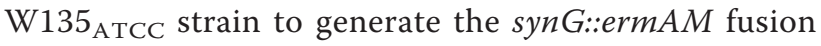
strain M6, erythromycin resistant (Figure 4).

The analysis of transformation index on SBA-15/SBA16 nanoparticles action is performed adding of each one in $1.10^{8}$ colony forming units (CFU) the receptor strain C2135 was added of $1 \mu \mathrm{g}$ of M2 or M6 genomic DNA and $30 \mu \mathrm{g}$ of different mesoporous silica in well plates (table 4 and Figure 5). A negative control was also performed without mesoporous silica. The suspension was 
Table 3 Oligonucleotides used in this work

\begin{tabular}{|c|c|c|}
\hline Oligonucleotide & Sequence $5^{\prime}-3^{\prime}$ & Description \\
\hline $03.12-3$ & TGCGGATCCGCAGTAATTTTATCGGTTGG & NMB0065 forward \\
\hline $03.12-4$ & CCCCACTACCTAAAAAATGCTGATTTG & NMB0065 reverse \\
\hline aadA1 & TGCCGTCACGCAACTGGTCCA & $\Omega a a D A$ forward \\
\hline aadA2 & CAACTGATCTGCGCGCGAGGC & SaaDA reverse \\
\hline 98.30 & GGTGAATCTTCCGAGCAGGAAA & synG forward \\
\hline 98.31 & AAAGCTGCGCGGAAGAATAGTG & synG reverse \\
\hline $03.12-5^{*}$ & TCGGGATCCTTATTITTCTTGGCCAAAAA & synG reverse \\
\hline 04.02-1 & CAATGAATCTCGCGTTGCTGTAGGTG & synG forward \\
\hline $04.02-2$ & GAAAAATAATTTGGGGCTTAGG & synG forward \\
\hline galECK29A & CTTCCATCATTTGTGCAAGGCTGC & gale reverse \\
\hline ERAM1 & GCAAACTTAAGAGTGTGTTGATAG & ermAM forward \\
\hline ERAM3 & AAGCTTGCCGTCTGAATGGGACCTCTITA GCTTCTTGG & ermAM reverse \\
\hline
\end{tabular}

${ }^{*}$ The underlined sequences in italic are the insertion of the BamHl site into original sequence

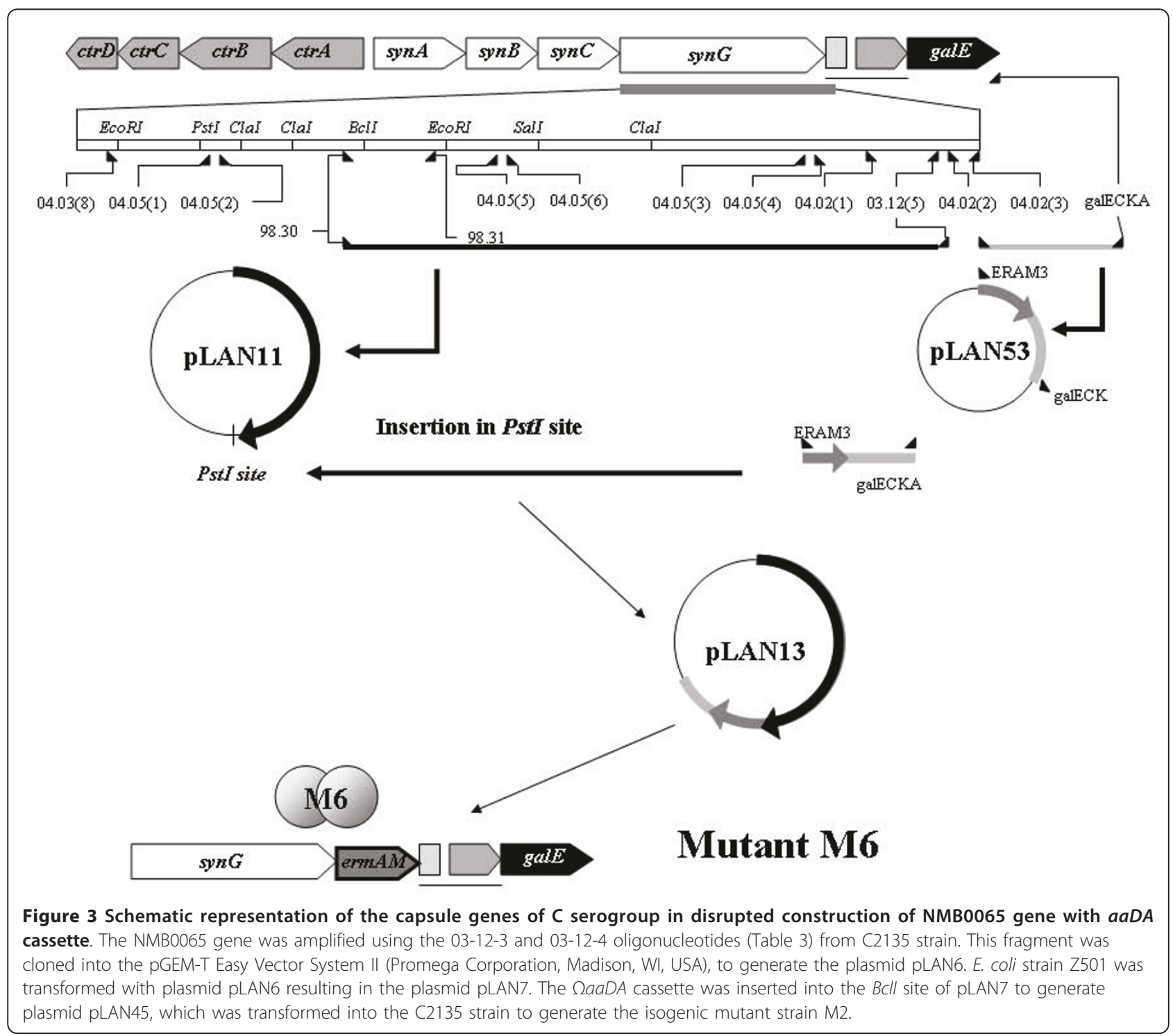


( $\alpha 2-9) \mathrm{N}$-acetyl neuraminic acid syntheis operon

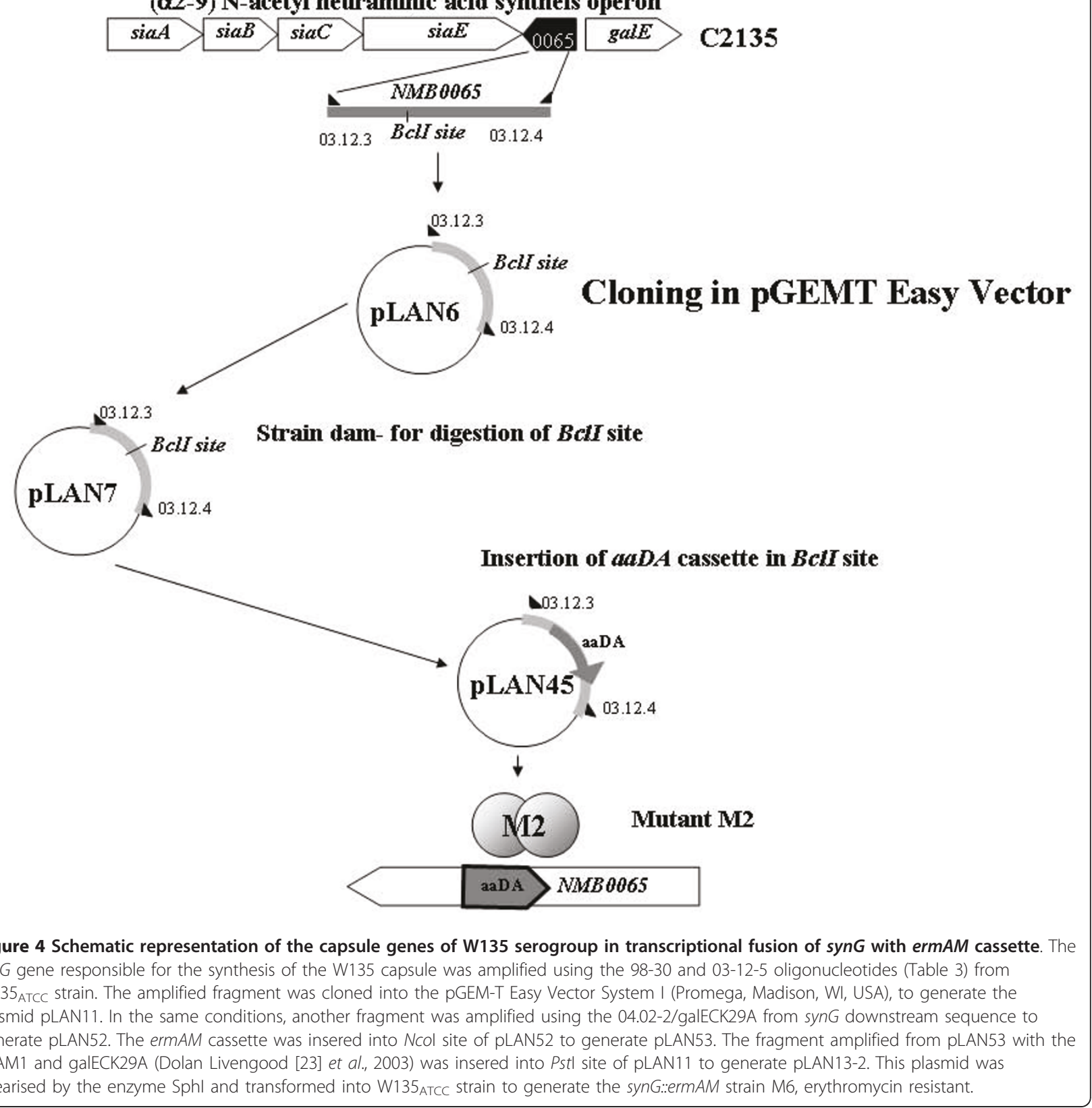

incubated at $37^{\circ} \mathrm{C}$ in $\mathrm{CO}_{2}$ atmosphere by three hours in these conditions. The counts of total cfu were performed in GCB spectinomycin or erythromycin plates in triplicate analysis (for M2 and M6 isogenic mutants respectively). The CFU obtained in plates containing specific antibiotic were analyzed by PCR, searching the presence of target gene transfer in the transforming units $(\Omega a a D A$ cassette for the M2 DNA and synG for M6 donor DNA).

The graphic of Figure 5 shows significant increase of transformation frequencies using M2 and M6 donor
DNA and the mesoporous silica SBA-15, SBA-16 and SBA-15/P(N-iPAAm). The use of a different DNA donor had as aim the certification of the independence of mesoporous silica effect on the same bacterial strain$N$. meningitidis C2135. The analysis of the PCR had demonstrated the transfer of the gene syn $G$ from M6 donor strains to $\mathrm{C} 2135$ receptor strain (data not showed).

The data analyses were made by ratio values between the numbers of transformants CFU obtained with mesoporous silica action by the median value of 
Table 4 Values obtained from C21 35 Transformation using the donor DNA from M2 and M6 mutants

\begin{tabular}{|c|c|c|c|}
\hline Donor DNA $(1 \mu \mathrm{g})$ & $\begin{array}{l}\text { Mean of the UCF transformants } \\
\text { obtained in } 1.10^{8} \text { UFC }\end{array}$ & $\begin{array}{l}\text { Ratio (means obtained exposed to silica/ } \\
\text { mean of negative control) }\end{array}$ & $\begin{array}{l}P \text { values (one way } \\
\text { Tukey's test) }\end{array}$ \\
\hline $\begin{array}{l}\text { Negative Control (without } \\
\text { mesoporous silica) M2 }\end{array}$ & $932 \pm 175,50$ & $1,00 \pm 0,11$ & \\
\hline SBa 15 + DNA M2 & $1696 \pm 73,30$ & $1,52 \pm 0,25$ & $(P<0,05)$ \\
\hline SBa 16 + DNA M2 & $1840 \pm 423,32$ & $1,97 \pm 0,22$ & $(P<0,05)$ \\
\hline SBa $15(\mathrm{P}(N$-iPAAm $)+$ DNA M2 & $1544 \pm 358,10$ & $1,38 \pm 0,05$ & $(P<0,05)$ \\
\hline $\begin{array}{l}\text { Negative Control (without } \\
\text { mesoporous silica) M6 }\end{array}$ & $106 \pm 10,00$ & $0,92 \pm 0,06$ & \\
\hline SBa 15 + DNA M6 & $364,33 \pm 117,11$ & $3,17 \pm 0,80$ & $0,0475(P<0,05)$ \\
\hline SBa 16 + DNA M6 & $558,70 \pm 59,56$ & $4,50 \pm 0,43$ & $0,0008(P<0,05)$ \\
\hline SBa 15 (P(N-iPAAm) + DNA M6 & $598,67 \pm 107,56$ & $5,20 \pm 0,80$ & $0,0058(P<0,05)$ \\
\hline
\end{tabular}

transformants CFU obtained without silica treatment. The values were analyzed by ANOVA one-way analysis of variance (Tukey test compared each treatment to control without mesoporous silica in transformation). The meningococci growth was not affected by the presence of mesoporous silica (data not shown).

As showed in table 4, the significant values of $\mathrm{P}<0.05$ obtained in the ratio values between transformation using the donors M2 and M6 mutants DNA, respectively. These values are considered significant when compared with the transformation frequency obtained from negative control without silica action. Thus, the actions of mesopourous silica under the meningococci transformation increased the capacity of the C2135 strains, specially using the construction M6, directly implicated in the capsular switching outbreaks.

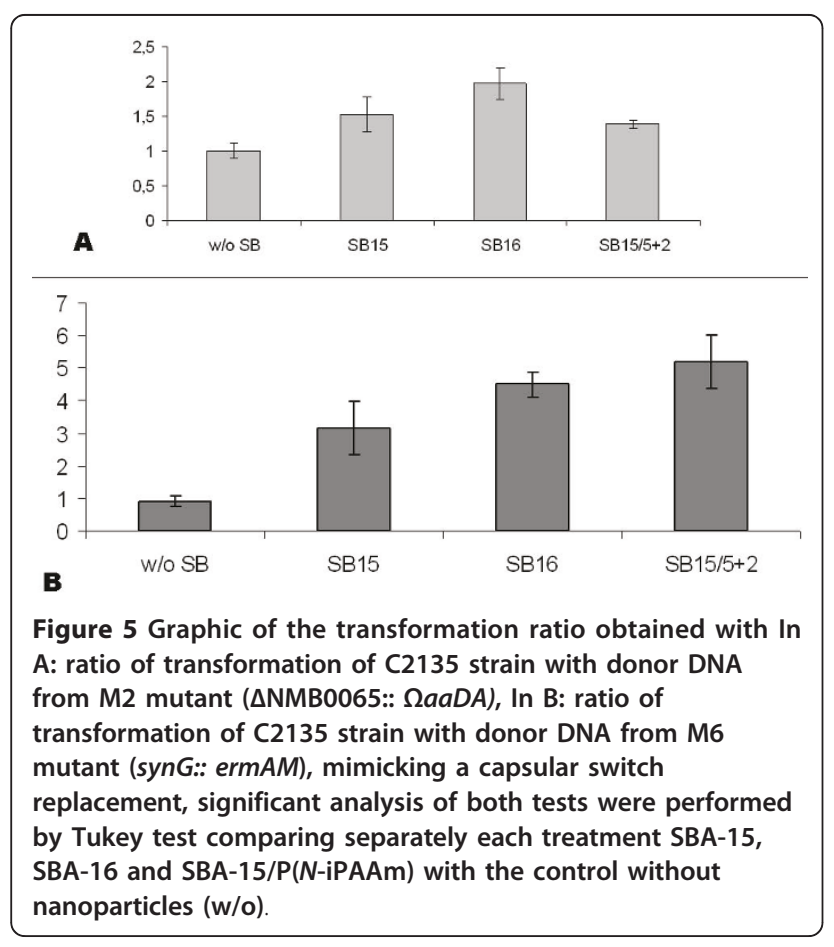

Despite the exact mechanism of the capsular switching is still under investigation, we proposed that this process is related to the action of mesoporous silica structures in the transformation frequencies in $1.10^{8} \mathrm{cfu}$, with a significant increase when mesoporous silica was used. The behavior of SBA-16, regarding to transformation process of C2135 strain with donor DNA from M2 mutant, was different from that observed for the others. This nanoparticle showed increase of transformation frequency more than SBA-15, and SBA-15/P(N-iPAAm) mesoporous silica. Besides the differences in the textural properties showed in Table 2, a probable cause for the different responses is the presence of singular morphological arrangements, as they are hierarchically organized in a special way. Moreover, it is worth noticing that the threedimensional interconnected pore structure of sample SBA-16 can facilitate the occurrence of adsorption.

The important information is the chromosomal localization of the NMB0065 and syn $G$ gene. Both are gene of bacterial chromosome and their biological characteristics determined in Neisseria meningitidis when these genes are recombined onto chromosomes level. Nevertheless, $N$. meningitidis rarely replicate the plasmids provided from E.coli constructions, as those performed in these work (plasmids from pLAN series), exceptionally when in the plasmid carrier antibiotic resistant from another species of Neisseria as N. gonorrhoeae [24-26].

Also the practical implications of the silica action under meningococci are very important to the workers that usually are exposed at these nanoparticles [27-29]. The careful action of adopting the safety measures not only the silicosis [30-33] but also for adopting safety mesures to prevent not only silicosis but also changing pathology and host adaptation of $N$. meningitidis, will be important in places where silica nanoparticles are present, especially in aerosols. This work is the first to cite the relationships between the silica risks of health caused by meningococcal capsular switching or capsular replacement. This neglected process is described just as an immunologically controlled phenomenon not 
involving the environmental influences such as the presence of the nanostructures in the atmosphere.

Nevertheless, the capsular switching is described in regions as the sub Saharan Africa [11,34-36] and Saudi Arabia (Hajj pilgrimage) [34,37-43] in desert zones where probably silica nanostructures are present that facilities the capsular switching process. New experiments using the animal models could confirm this hypothesis and has been performed by the research group for Neisseria meningitdis and other natural competent bacteria as Streptococcus pneumoniae and Haemophilus influenzae.

\section{Acknowledgements}

This study has been financier supported by CAPES, FAPESP, CNPq and FAPEMIG. These supports help us to reagent supply and equipments for all this research development. FAPESP (number 2008/56777-5) and CNPq (number 575313/2008-0) funding the Laboratory of Biotechnology (Coordinated by M.L.). FAPEMIG funding the laboratory coordinated by E.M.B. S. CNPq and CAPES funding with the personal fellowships for students: R.F.C. P., AS and GAF. Thanks for the English revision for Luiz Paulo Manzo, Júlia N. Varela and Maria Cecília T. Amstalden.

\section{Author details}

'Department of Biochemistry, Institute of Biology CP6109, State University of Campinas UNICAMP, CP: 6109-CEP 13083-970, Campinas, SP, Brazil. ${ }^{2}$ National Commission of Nuclear Energy, Center of Development of Nuclear Energy, Nanotechnology Services. CP: 941-CEP 30123-970, Belo Horizonte, MG, Brazil.

\section{Authors' contributions}

LH carried out the molecular genetic studies; GC carried out the Molecular Biology design and plasmids; RP carried out the molecular microbiologic tests; GF carried out the mesoporous silica electronic microscopy; AS carried out the mesoporous silica synthesis; ES carried out the mesoporous silica synthesis and design, participated in the sequence alignment and drafted the manuscript; $\mathbf{M L}$ carried out the molecular genetic studies, participated in the sequence alignment and drafted the manuscript.

All the authors read and approved the final manuscript.

\section{Competing interests}

The authors declare that they have no competing interests.

Received: 12 March 2011 Accepted: 25 July 2011

Published: 25 July 2011

\section{References}

1. Tonjum T, Koomey M: The pilus colonization factor of pathogenic neisserial species: organelle biogenesis and structure/function relationships-a review. Gene 1997, 192:155-163.

2. Goodman SD, Scocca JJ: Factors influencing the specific interaction of Neisseria gonorrhoeae with transforming DNA. J Bacteriol 1991, 173:5921-5923.

3. Swartley JS, Marfin AA, Edupuganti S, Liu LJ, Cieslak P, Perkins B, Wenger JD, Stephens DS: Capsule switching of Neisseria meningitidis. Proc Natl Acad Sci USA 1997, 94:271-276.

4. Zhou D, Stephens DS, Gibson BW, Engstrom JJ, McAllister CF, Lee FK, Apicella MA: Lipooligosaccharide biosynthesis in pathogenic Neisseria. Cloning, identification, and characterization of the phosphoglucomutase gene. J Biol Chem 1994, 269:11162-11169.

5. Stephens DS, McGee ZA, Melly MA, Hoffman LH, Gregg CR: Attachment of pathogenic Neisseria to human mucosal surfaces: role in pathogenesis. Infection 1982, 10:192-195.

6. Alonso JM, Guiyoule A, Zarantonelli ML, Ramisse F, Pires R, Antignac A, Deghmane AE, Huerre M, van der Werf S, Taha MK: A model of meningococcal bacteremia after respiratory superinfection in influenza A virus-infected mice. FEMS Microbiol Lett 2003, 222:99-106.
7. Nassif X, So M: Interaction of pathogenic neisseriae with nonphagocytic cells. Clin Microbiol Rev 1995, 8:376-388.

8. Spinosa MR, Progida C, Tala A, Cogli L, Alifano P, Bucci C: The Neisseria meningitidis capsule is important for intracellular survival in human cells. Infect Immun 2007, 75:3594-3603.

9. Frosch M, Muller D, Bousset K, Muller A: Conserved outer membrane protein of Neisseria meningitidis involved in capsule expression. Infect Immun 1992, 60:798-803.

10. Taha MK, Parent Du Chatelet I, Schlumberger M, Sanou I, Djibo S, de Chabalier F, Alonso JM: Neisseria meningitidis serogroups W135 and A were equally prevalent among meningitis cases occurring at the end of the 2001 epidemics in Burkina Faso and Niger. J Clin Microbiol 2002, 40:1083-1084.

11. Taha MK, Antignac A, Renault P, Perrocheau A, Levy-bruhl D, Nicolas P, Alonso JM: Clonal spread of Neisseria meningitidis W135. Presse Med 2001, 30:1535-1538.

12. Lancellotti M, Guiyoule A, Ruckly C, Hong E, Alonso JM, Taha MK: Conserved virulence of $C$ to $B$ capsule switched Neisseria meningitidis clinical isolates belonging to ET-37/ST-11 clonal complex. Microbes Infect 2006, 8:191-196.

13. Zarantonelli ML, Lancellotti M, Deghmane AE, Giorgini D, Hong E, Ruckly C, Alonso JM, Taha MK: Hyperinvasive genotypes of Neisseria meningitidis in France. Clin Microbiol Infect 2008, 14:467-472.

14. Kriz P, Kriz B, Svandova E, Musilek M: Antimeningococcal herd immunity in the Czech Republic-influence of an emerging clone, Neisseria meningitidis ET-15/37. Epidemiol Infect 1999, 123:193-200.

15. Alcala B, Salcedo C, Arreaza L, Abad R, Enriquez R, De La Fuente L, Uria MJ, Vazquez JA: Antigenic and/or phase variation of PorA protein in nonsubtypable Neisseria meningitidis strains isolated in Spain. J Med Microbiol 2004, 53:515-518.

16. Perez-Trallero E, Vicente D, Montes M, Cisterna R: Positive effect of meningococcal $C$ vaccination on serogroup replacement in Neisseria meningitidis. Lancet 2002, 360:953.

17. Stefanelli P, Fazio C, Neri A, Sofia T, Mastrantonio P: First report of capsule replacement among electrophoretic type 37 Neisseria meningitidis strains in Italy. J Clin Microbiol 2003, 41:5783-5786.

18. Taha MK, Bichier E, Perrocheau A, Alonso JM: Circumvention of herd immunity during an outbreak of meningococcal disease could be correlated to escape mutation in the porA gene of Neisseria meningitidis. Infect Immun 2001, 69:1971-1973.

19. Zarantonelli ML, Antignac A, Lancellotti M, Guiyoule A, Alonso JM, Taha MK Immunogenicity of meningococcal PBP2 during natural infection and protective activity of anti-PBP2 antibodies against meningococcal bacteraemia in mice. J Antimicrob Chemother 2006, 57:924-930

20. Taha MK, Morand PC, Pereira Y, Eugene E, Giorgini D, Larribe M, Nassif X: Pilus-mediated adhesion of Neisseria meningitidis: the essential role of cell contact-dependent transcriptional upregulation of the PilC1 protein. Mol Microbiol 1998, 28:1153-1163.

21. Souza KC, Ardisson JD, Sousa EM: Study of mesoporous silica/magnetite systems in drug controlled release. J Mater Sci Mater Med 2009, 20:507-512.

22. Giorgini D, Taha MK: Molecular typing of Neisseria meningitidis serogroup A using the polymerase chain reaction and restriction endonuclease pattern analysis. Mol Cell Probes 1995, 9:297-306.

23. Dolan-Livengood JM, Miller YK, Martin LE, Urwin R, Stephens DS: Genetic basis for nongroupable Neisseria meningitidis. J Infect Dis 2003, 187:1616-1628.

24. Dillon JR, Pauze M, Yeung KH: Spread of penicillinase-producing and transfer plasmids from the gonococcus to Neisseria meningitidis. Lancet 1983, 1:779-781.

25. Ikeda F, Tsuji A, Kaneko Y, Nishida M, Goto S: Conjugal transfer of betalactamase-producing plasmids of Neisseria gonorrhoeae to Neisseria meningitidis. Microbiol Immunol 1986, 30:737-742.

26. Naessan CL, Egge-Jacobsen W, Heiniger RW, Wolfgang MC, Aas FE, Rohr A, Winther-Larsen HC, Koomey M: Genetic and functional analyses of PptA, a phospho-form transferase targeting type IV pili in Neisseria gonorrhoeae. J Bacteriol 2008, 190:387-400.

27. Abraham JL, McEuen DD: Inorganic particulates associated with pulmonary alveolar proteinosis: SEM and X-ray microanalysis results. Appl Pathol 1986, 4:138-146. 
28. van den Brule S, Misson P, Buhling F, Lison D, Huaux F: Overexpression of cathepsin $\mathrm{K}$ during silica-induced lung fibrosis and control by TGF-beta. Respir Res 2005, 6:84.

29. Barboza CE, Winter DH, Seiscento M, Santos Ude P, Terra Filho M: Tuberculosis and silicosis: epidemiology, diagnosis and chemoprophylaxis. J Bras Pneumol 2008, 34:959-966.

30. Ding M, Chen F, Shi X, Yucesoy B, Mossman B, Vallyathan V: Diseases caused by silica: mechanisms of injury and disease development. Int Immunopharmacol 2002, 2:173-182.

31. Harrison J, Chen JQ, Miller W, Chen W, Hnizdo E, Lu J, Chisholm W, Keane M, Gao P, Wallace W: Risk of silicosis in cohorts of Chinese tin and tungsten miners and pottery workers (II): Workplace-specific silica particle surface composition. Am J Ind Med 2005, 48:10-15.

32. Hearl FJ: Industrial hygiene sampling and applications to ambient silica monitoring. J Expo Anal Environ Epidemiol 1997, 7:279-289.

33. Linch KD: Respirable concrete dust-silicosis hazard in the construction industry. Appl Occup Environ Hyg 2002, 17:209-221.

34. Alonso JM, Bertherat E, Perea W, Borrow R, Chanteau S, Cohet C, Dodet B, Greenwood B, LaForce FM, Muros-Le Rouzic E, et al: From genomics to surveillance, prevention and control: new challenges for the African meningitis belt. Bull Soc Pathol Exot 2006, 99:404-408.

35. Caugant DA, Nicolas P: Molecular surveillance of meningococcal meningitis in Africa. Vaccine 2007, 25(Suppl 1):A8-11.

36. Zombre S, Hacen MM, Ouango G, Sanou S, Adamou Y, Koumare B, Konde MK: The outbreak of meningitis due to Neisseria meningitidis W135 in 2003 in Burkina Faso and the national response: main lessons learnt. Vaccine 2007, 25(Suppl 1):A69-71.

37. Dull PM, Abdelwahab J, Sacchi CT, Becker M, Noble CA, Barnett GA, Kaiser RM, Mayer LW, Whitney AM, Schmink S, et al: Neisseria meningitidis serogroup W-135 carriage among US travelers to the $2001 \mathrm{Hajj}$. I Infect Dis 2005, 191:33-39.

38. Taha MK, Giorgini D, Ducos-Galand M, Alonso JM: Continuing diversification of Neisseria meningitidis W135 as a primary cause of meningococcal disease after emergence of the serogroup in 2000. J Clin Microbiol 2004, 42:4158-4163.

39. Wang JL, Liu DP, Yen JJ, Yu CJ, Liu HC, Lin CY, Chang SC: Clinical features and outcome of sporadic serogroup W135 disease Taiwan. BMC Infect Dis 2006, 6:7.

40. Wilder-Smith A: W135 meningococcal carriage in association with the Hajj pilgrimage 2001: the Singapore experience. Int J Antimicrob Agents 2003, 21:112-115.

41. Wilder-Smith A: Meningococcal vaccine in travelers. Curr Opin Infect Dis 2007, 20:454-460.

42. Wilder-Smith A, Barkham TM, Chew SK, Paton NI: Absence of Neisseria meningitidis W-135 electrophoretic Type 37 during the Hajj, 2002. Emerg Infect Dis 2003, 9:734-737.

43. Wilder-Smith A, Barkham TM, Earnest A, Paton NI: Acquisition of W135 meningococcal carriage in Hajj pilgrims and transmission to household contacts: prospective study. Bmj 2002, 325:365-366.

44. Hanahan D: Studies on transformation of Escherichia coli with plasmids. J Mol Biol 1983, 166:557-580

doi:10.1186/1477-3155-9-28

Cite this article as: Hollanda et al:: Effect of mesoporous silica under Neisseria meningitidis transformation process: environmental effects under meningococci transformation. Journal of Nanobiotechnology 2011 9:28.

\section{Submit your next manuscript to BioMed Central and take full advantage of:}

- Convenient online submission

- Thorough peer review

- No space constraints or color figure charges

- Immediate publication on acceptance

- Inclusion in PubMed, CAS, Scopus and Google Scholar

- Research which is freely available for redistribution 